\title{
Bariatric Surgery in Super-Superobese Patients Maintains Metabolic Improvement Beyond The Failure in Expected Weight Loss.
}

Sergio Susmallian ( $\nabla$ sergio9@bezeqint.net)

Assuta Medical Center

Asnat Raziel

Assuta Medical Center

Irena Babis

Assuta Medical Center

Royi Barnea

Assuta Medical Center

\section{Research Article}

Keywords: Bariatric surgery, Weight reduction, mortality, outcomes.

Posted Date: September 30th, 2021

DOI: https://doi.org/10.21203/rs.3.rs-917329/v1

License: (1) This work is licensed under a Creative Commons Attribution 4.0 International License. Read Full License 


\section{Abstract \\ Background}

Extreme obesity leads to increased health risks and perioperative complications. The results of bariatric surgery in patients with super-super obesity (SSO) are presented in this study.

\section{Methods}

From April 2008 to August 2019, 60 patients with SSO underwent bariatric surgery. Their weight loss and surgical outcome were analyzed. The mean follow-up time was 7.2 years.

\section{Results}

At baseline, the mean age was 41.5 years old, the mean BMI was $63.8 \mathrm{~kg} / \mathrm{m} 2,80 \%$ of the patients suffered from co-morbidities, and $23.33 \%$ were revisional surgeries. Weight loss continued for up to two years after surgery. The percentage of EBW lost at two years was $62.27 \%$, from two to five years: $61.48 \%$, from five to 10 years: $36.82 \%$ and after ten years it was $31.89 \%$, the differences in weight change over the time is significative $(P<.001)$. The mean BMl at last visit (Mean 7.2 years) was $45.1 \mathrm{~kg} / \mathrm{m} 2$ and $48.33 \%$ of the patients failed to lose at least $50 \%$ of EBW. Patients with fatty liver, diabetes, sleep apnea and hyperlipidemia had a remission or improvement in more than $70 \%$ of the cases. There were $5 \%$ perioperative complications, one perioperative death (1.67\%) and other patient died in a motor vehicle accident, overall mortality $3.33 \%$.

\section{Conclusion}

In the long term, almost half of the patients failed to lose $50 \%$ of their EBW. However, the metabolic effects of bariatric surgery were maintained during the follow-up time with a high remission of comorbidities. Revisional bariatric surgery increased the risk of mortality.

\section{Introduction}

Obesity is a complex disease of multifaceted etiology with its own associated disabilities, pathophysiology, and co-morbidities ${ }^{1}$. The number of obese people is constantly increasing and has almost tripled worldwide in the last five decades ${ }^{2}$. Obesity is a significant risk factor and contributes to increased morbidity and mortality, mainly from cardiovascular diseases and diabetes, but also from cancer, osteoarthritis, liver and kidney diseases, sleep apnea, and depression ${ }^{3}$. Excess adipose tissue increases the work of the heart and leads to cardiac anatomical changes, alters the lungs, the endocrine system, and immune functions, all with adverse health effects ${ }^{4}$. There is a curvilinear increase in the risk 
of mortality as a function of weight; patients with a BMI $\geq 60$ have a risk of mortality of more than $275 \%$ due to all causes ${ }^{5}$.

Weight loss appears to be the most effective therapy for obesity and obesity-related co-morbidities ${ }^{6}$. Therefore, a 5-10\% weight loss provides considerable benefit in reducing health risks ${ }^{7}$.

Conservative treatments, such as diet, physical exercise, medicaments, and behavior modifications revealed a lack of long-term efficacy in patients with extremely high BMI $(\geq 60 \mathrm{~kg} / \mathrm{m} 2)^{8}$.

With the failure of medical treatment for obesity, patients turn to more aggressive treatments, such as bariatric surgery, to achieve weight loss ${ }^{9}$. Bariatric surgery leads to a substantial improvement in comorbidities, as well as a reduction in overall mortality by $25-50 \%$ during long-term follow-up ${ }^{10}$.Bariatric surgical procedures resulted in significant weight loss and an expected and lasting weight loss of approximately $50 \%$ of EBW, with improvement or resolution of most of the conditions associated with obesity ${ }^{11}$. Surgery causes metabolic changes that favor weight loss and associated co-morbidities compared to non-surgical interventions, regardless of the type of procedures used ${ }^{12}$. The fundamental basis of bariatric surgery in order to achieve weight loss is the determination that severe obesity is a disease associated with multiple adverse effects on health ${ }^{13}$.

Bariatric surgery has been shown to be feasible and has an acceptable complication rate for $\mathrm{SSO}^{14}$. That said, the implications for the anesthetic and perioperative care of severely obese patients who undergo weight loss procedures are considerable in $\mathrm{SSO}^{15}$. Unfortunately, there are very few published data examining and comparing the surgical outcomes in patients with SSO with any of the known bariatric procedures $^{16}$.

The long-term results of bariatric surgery in patients with OHS have not been conclusively determined, so the aim of this study is to analyze the results of different types of surgery in patients with BMl $\geq 60 \mathrm{~kg} /$ $\mathrm{m} 2$.

\section{Materials \& Methods}

A retrospective cohort study was performed in patients with $B M I \geq 60 \mathrm{~kg} / \mathrm{m}^{2}$ that underwent bariatric surgery in a private network of medical centers for elective surgery from April 2008 until August 2019. The patient data were collected from the institutional registry and included: age, demographic information, surgery types, and co-morbidities.

Remission of co-morbidity was considered when the signs and symptoms disappear, with no abnormal laboratory tests and without medications, improvements were considered when decrease symptoms and signs of the disease, diminish medications of better labs results. Inclusion criteria included patients 18 years of age or older, complete registry availability, primary and revisional surgeries, and at least one-year post-operative. Follow-up data were obtained from periodical patient visits and reviewing medical 
histories from the health insurance database. The study was approved by the Assuta Helsinki review board (Number 2015-073) and registered in Clinicaltrials.gov (number NCT04663425), first posted $11 / 12 / 2020$. The study is retrospective observational one, so written informed consent was waived by the Helsinki Committee Board Assuta Medical Center.

During the study period, 33,726 bariatric procedures were performed in our Institutions according to the criteria developed by the National Institutes of Health $(\mathrm{NIH})$ Consensus Development Conference Panel in 1991; the recommendations for bariatric surgery are: a $\mathrm{BMI} \geq 40 \mathrm{~kg} / \mathrm{m}^{2}$ or a $\mathrm{BMI} \geq 35 \mathrm{~kg} / \mathrm{m}^{2}$ in combination with high-risk comorbid conditions ${ }^{17}$.

\section{Statistical Analysis}

Demographic patient data included: age, gender, BMI, weight, and height as well as medical history, previous bariatric surgeries and procedures, chronic treatments, use of medications.

Changes in weight were provided as BMI, EBW, and percent of weight loss. Due to the lack of unanimous criteria for bariatric surgery failure, we elected to use the following two levels of criteria to determine what constituted a failure: a weight loss of $25 \%$ or less of the EBW ${ }^{18-19}$ or less than $50 \%$ loss of weight ${ }^{20,21}$. Continuous variable summary tables were provided giving frequencies, arithmetic means with standard deviation, and $95 \% \mathrm{Cl}$ (Confidence Interval). Normally distributed variables were compared using an independent samples t-Test and Chi-square test was used to compare counts. Statistical analysis was performed using the SPSS statistical package, Version 21 (SPSS Inc, Chicago, IL, USA). All p-values were 2-sided and $p<.05$ was considered statistically significant.

\section{Results}

\section{Baseline Patient characteristics.}

The patients who were identified with $\mathrm{BMI} \geq 60$ comprised 60 cases, which represented $0.18 \%$ of all bariatric surgeries performed at the Medical Center. The mean age of the population was 41.5 years old (range 18 to 69 ), male to female ratio $1: 2$, the mean baseline BMI was $63.8 \mathrm{~kg} / \mathrm{m}^{2}$ (range 60 to 89). Obesity-related diseases were present in $80 \%$ of the patients and the remaining $20 \%$ did not present a history of obesity-associated diseases (Table 1).

\section{Interventions}

All patients underwent a laparoscopic approach for bariatric surgery. Laparoscopic sleeve gastrectomy (LSG) was performed on 40 patients, 15 patients underwent laparoscopic one anastomosis gastric bypass (LOAGB), five patients underwent laparoscopic roux en-y-gastric bypass (LRYGB). For 49 (81.67\%) patients it was their first bariatric procedure and for 11 patients $(18.33 \%)$ it was revisional surgery. In the group of patients that undergone revisional surgery, 10 patients had previously underwent laparoscopic adjustable gastric band (LAGB). Out of those patients, two of them underwent LAGB 3-times, and one 
underwent LAGB 2-times. One patient previously had a LSG after LAGB. In five patients (8.33\%) the LAGB was removed at the same time. In 4 patients it was converted to LSG, 5 to LRYGBP and 2 to LOGBP.

In two patients (3.33\%) cholecystectomies were performed, and in two patients (3.33\%) repairs of hiatal hernia were required and one repair of an incisional hernia. The mean operative time was 126.135 ( \pm 63.32 ) minutes: 121.80 minutes for LSG, 115 minutes for LOAGB, and 194.4 minutes for LRYGB $(p=.004)$. The long operative time for LRYGB can be explained since it involves revisional surgeries. The mean operative time for primary surgeries was 121.02 (SD \pm 69.12$)$ minutes, and for revisional surgeries $159.21(S D \pm 62.73)$, without significant statistical difference $(p=.080)$.

\section{Follow-up}

On the date of analysis (December 31,2020$)$ the mean follow-up time was 7.2 years $(S D \pm 39.271)$. Four $(6.66 \%)$ of the patients were followed for 2 years, $24(40 \%)$ patients were followed between 2 to 5 years, $25(41.67 \%)$ patients were followed from 5 to 10 years, and seven $(11.67 \%)$ patients were followed for more than 10 years. During the follow-up period, the percentage of weight loss decreased over time. The mean percentage of weight loss until two years was $62.27 \%$, from two to five years it was $61.48 \%$, from 5 to 10 years it was $36.82 \%$, and after ten years it was $31.89 \%(P<.001)$, shown in Figure 1 .

\section{Weight loss}

The mean weight at the last follow-up after the operation was $121.84 \mathrm{~kg}$, the mean BMI was $45.11 \mathrm{~kg} / \mathrm{m}^{2}$, and the mean percentage of excess body weight (EBW) lost was $48.66 \%$. Eleven (18.33\%) patients lost less than $25 \%$ of EBW and $29(48.33 \%)$ patients lost less than $50 \%$ of EBW (Figure 2$)$. According to the type of bariatric surgery, the mean weight loss of the 15 patients who underwent LOAGB was $61.2 \%$ of EBW (SD $\pm 23.77,95 \% \mathrm{Cl}$ : $40.214-88.266$ ), the 40 patients who underwent a LSG lost $45.27 \%$ of EBW (SD $\pm 22.75,95 \% \mathrm{Cl}: 37.240-56.080)$ of the original weight, and the five patients who underwent a LRYGB lost $35.28 \%$ of EBW (SD $\pm 19.087,95 \% \mathrm{Cl}$ : $28.866-99.426)$, LOAGB procedure showed higher weight loss but, without statistical significance $(p=.054)$.

Patients that underwent primary bariatric surgery lost an average of $48.54 \%$ (SD $\pm 23.03,95 \%$ Cl: 45.347$59.973)$ of their EBW while patients that underwent revisional surgeries lost $36.38 \%$ (SD $\pm 22.61,95 \% \mathrm{Cl}$ : 15.634-67.886) of their EBW ( $p=.118)$ (Figure 3). In the patients that failed to lose at least $50 \%$ of EBW, 24 (60\%) patients had LSG surgery, 3 (20\%) patients had LOAGB, and $3(60 \%)$ patients had LRYGB, however, the difference was not statistically significant $(p=.245)$.

\section{Co-morbidities}

A total of $48(80 \%)$ patients presented with morbidities associated to obesity. The most common comorbidities were fatty liver, diabetes Type II, hypertension, hyperlipidemia, and sleep apnea (Table 2). The fatty liver, sleep apnea, reflux disease, and diabetes had a high proportion of remission or improvement. Conversely, hypertension had a low rate of improvement, and hyperlipidemia had low rate of remission. 
It is noteworthy, that despite the fact that weight loss has not been sufficient in almost half of the patients; the metabolic changes induced by bariatric surgery persist during follow-up. Fatty liver had a remission or improved in $73.91 \%$ of patients, and the remaining $26.09 \%$ of unchanged patients were among those who did not lose weight. Patients with diabetes mellitus type II, $77.78 \%$ remission or improved, while $38.89 \%$ were able to maintain normal levels of plasma glucose and hemoglobin A1C, the $22.22 \%$ of the patients who continued with the same medication regiment were among those who failed to lose weight. Sleep apnea was in remission in $71.43 \%$ of the patients and improve in $14.29 \%$ and there was only one patient without who remained unchanged. All the patients who reported reflux before the operation were asymptomatic at the end of the follow-up. Hyperlipidemia had improved or been in remission in $70 \%$ of the patients and hypertension improved in $29.1 \%$ of the patients.

\section{Perioperative complications}

There was one perioperative death (1.67\%) due to a post-operative leak after LOAGB and the same patient had previously undergone LAGB and LSG. The second death was due to a motor vehicle accident two years after surgery. The overall perioperative mortality of patients who underwent bariatric surgery for any $\mathrm{BMI}$, in our institution, was $0.04 \%$. One death $(10 \%)$ occurred in the group of revisional bariatric surgery (11 patients) and one (2.08\%) in the primary bariatric surgery group (49 patients), the risk ratio is 7.92 and the Odds ratio 4.8. When compared with the mortality of patients with $B M I \geq 60 \mathrm{~m} / \mathrm{kg}^{2}$, the difference is statistically significant $(p<.001)$. There were three $(5 \%)$ patients with perioperative complications, one with an anastomotic leak, one patient presented with supraventricular tachycardia, and one patient with a superficial site infection. No blood products were needed and there was no need for re-admissions.

\section{Discussion}

Extreme obesity carries risks of severe co-morbidities, psychological disorders, social isolation, and many other disadvantages, as well as increased mortality ${ }^{22}$. A difficult question to answer is whether obesity in patients with $B M I \geq 60$ is due to the same pathophysiology as patients with $B M I \geq 40$, or if there are other associated factors. The loss of the sense of satiety is a decisive factor in the development of extreme obesity ${ }^{23}$. There is a growing interest in the identification of satiety phenotypes that operate in parallel with metabolic phenotypes ${ }^{24}$.

Bariatric surgery in patients with SSO could be a risky procedure from the point of view of anesthesiology and postoperative management in relation to systemic diseases. Aggressive preoperative optimization can avert the effects of BMI on anesthetic outcomes ${ }^{25}$. The proportion of patients with SSO in our Institution was $0.18 \%$ of the total bariatric patients and was far less than that reported by Courcoulas, which was $12 \%$ of 2559 patients ${ }^{26}$. In this group, patients with LAGB failed in weight loss and quality of life improvement and had to remove the band and convert it into another type of operation. In a comparison of procedures in super-morbid obesity patients reported by Bettencourt-Silva, they showed that LAGB was the metabolic surgery with the least effective results, with only $21.7 \%$ of EBW loss ${ }^{27}$. 
Although, there are authors, who promote the use of $\mathrm{LAGB}^{28,29}$, our results in SSO patients show that LAGB should not be offered to these patients. Our results were in line with Cho who reported a high percentage of band removal in more than $37 \%$ of his patients, generally due to intolerance, slippage, or erosion ${ }^{30}$. Langer reported that the resection of the gastric fundus, the predominant area of human ghrelin production, significantly reduced ghrelin after LSG but not after $L A G B^{31}$. This reduction remains stable at follow-up 6 months postoperatively, which may contribute to the superior weight loss when compared with LAGB.

LSG and LRYGB offer good results in weight loss for SSO patients. LSG has demonstrated effective and satisfactory long-term results without the need for conversion to another type of metabolic surgery in patients with risks and extreme obesity ${ }^{32}$. Patients that underwent LSG had a mean loss of $46.66 \%$ EBW, with a mean BMI of $64 \mathrm{~kg} / \mathrm{m} 2$ before surgery and $46.44 \mathrm{~kg} / \mathrm{m} 2$ after surgery. These results are acceptable and did not have higher complications, coinciding with Villamere that LSG is safe without increased risk ${ }^{33}$. Gonzalez-Heredia's study reported poor weight loss after LSG $^{34}$, however, in our study, the weight loss for patients who underwent LSG was acceptable, even in the long-term follow-up, as demonstrated by Arapis $^{35}$.

We agree with Nesser that LRYGB offers the best results among restrictive surgeries ${ }^{36}$. In our group of patients, the results were altered by the fact that all the patients who underwent a LRYGB were revisional. None of our patients underwent malabsorptive surgery, which can be explained by the lack of compliance in this group of patients. Marek asserts in his study, that patients with a BMI $\geq 60$ had greater psychosocial sequelae, as demonstrated by more binge-eating episodes, and higher prevalence of major depressive disorders ${ }^{37}$.

The results of this study show more optimal results in terms of weight loss after LOAGB, coinciding with the results of Madhoc that reported EBW loss of $70.4 \%^{38}$.

In this study, the results reveal a high index of failure to lose weight in more than $48 \%$ of the patients. Preoperative factors that can predict inadequate weight loss include higher BMI, diabetes, and older age $^{39}$. Preoperative excessive BMl, especially, $\geq 60$, implies a lower percentage of weight loss will occur. Comparatively, while less obese (BMI $\leq 50)$ individuals continued losing weight, heavier individuals $(B M I \geq 50)$ regained significant weight ${ }^{40}$. Although the weight loss may be insufficient, it does not imply loss of the metabolic effect of bariatric surgery ${ }^{41}$. The results of the present study demonstrate metabolic changes through a high rate of remission or improvement in fatty liver, diabetes Type II, sleep apnea, asthma, and knee and back pain. Although diabetes has a high rate of remission or improvement, Runkel explains that this depends on the severity and duration of diabetes ${ }^{42}$.

Revisional surgery is an important factor to discuss since in SSO there are other uncontrollable factors that influence weight regain. We accept the criteria set forth by Lunel, which indicates that candidates for 
a third revision surgery should be considered cautiously ${ }^{43}$. In this group of patients, the only perioperative death occurred after third bariatric surgery.

There was no higher complication index in surgeries for patients with a $\mathrm{BMI} \geq 60$, coinciding with the report by Kushnir ${ }^{44}$. Bennet, in a study of mortality in bariatric surgery, found that mortality is related to age, and male sex, not finding a relationship with the increase in BMI as in our study ${ }^{45}$. We suggest considering revisional surgery cases as a risk factor in addition to age, gender, and health conditions.

The limitations of the study were the low number of patients and the completion of follow-up beyond 10 years in few patients.

The strengths of the study are that it provides long-term results of weight loss and metabolic changes from restrictive procedures as treatment in patients suffering from SSO.

\section{Conclusion}

In the long term, half of the patients failed to lose $50 \%$ of their EBW. However, the metabolic effects of bariatric surgery were maintained during the follow-up time with a high remission of co-morbidities. Bariatric surgery in patients with SSO was feasible with acceptable perioperative complications and higher mortality rate. Revisional bariatric surgery increased the risk of mortality.

\section{Declarations}

Acknowledgements: The authors would like to thank the CEO of Assuta Medical Centers for their support to carry out academic studies.

Author contributions: SS and AR write the main article, SS and RB preparted figures, SS and IB: collected the data. All the authors reviewed the manuscript.

Competing interests: All the authors declare no Competing interests

Clinical trial: Clinicaltrials.gov (number NCT04663425), first posted 11/12/2020

https://clinicaltrials.gov/ct2/show/NCT04663425

\section{References}

1. Conway, B. \& Rene, A. Obesity as a disease: no lightweight matter. Obes. Rev, 5 (3), 145-151 https://doi.org/10.1111/j.1467-789X.2004.00144.x (2004).

2. World Health Organization. Obesity and overweight. World Health Organization Website. http://www.who.int/news-room/fact-sheets/detail/obesity-and-overweight. Published 2018. 
3. Pi-Sunyer, X. The medical risks of obesity. Postgrad Med, 121 (6), 21-33 https://doi.org/10.3810/pgm.2009.11.2074 (2009).

4. Conway, B. \& Rene, A. Obesity as a disease: no lightweight matter. Obes Rev, 5 (3), 145-151 https://doi.org/10.1111/j.1467-789X.2004.00144.x (2004).

5. Dixon, J. B. The effect of obesity on health outcomes. Mol Cell Endocrinol, 316 (2), 104-108 https://doi.org/10.1016/j.mce.2009.07.008 (2010).

6. Bray, G. A. et al. The Science of Obesity management: An Endocrine Society Scientific Statement. Endocr Rev, 39 (2), 79-132 https://doi.org/10.1210/er.2017-00253 (2018).

7. Orlando, G. et al. The role of a multidisciplinary approach in the choice of the best surgery approach in a super-super-obesity case. International Journal of Surgery, 12, S103-106 https://doi.org/10.1016/j.jijsu.2014.05.037 (2014).

8. Deitel, M. \& Shikora, S. A. The development of the surgical treatment of morbid obesity. Journal of the American College of Nutrition, 21 (5), 365-371 https://doi.org/10.1080/07315724.2002.10719237 (2002).

9. Hainer, V., Toplak, H. \& Mitrakou, A. Treatment modalities of obesity: what fits whom?, 31 (Suppl 2), S269-277 https://doi.org/10.2337/dc08-s265 (2008).

10. Orlando, G. et al. The role of a multidisciplinary approach in the choice of the best surgery approach in a super-super-obesity case. International Journal of Surgery, 12, S103-106 https://doi.org/10.1016/j.jiju.2014.05.037 (2014).

11. Carmichael, A. R. Treatment for morbid obesity. Postgraduate medical journal, 75 (879), 7-12 https://doi.org/10.1136/pgmj.75.879.7 (1999).

12. Wolfe, B. M., Kvach, E. \& Eckel, R. H. Treatment of Obesity: Weight Loss and Bariatric Surgery. Circ Res, 118 (11), 1844-1855 https://doi.org/10.1161/CIRCRESAHA.116.307591 (2016).

13. Colquitt, J. L., Pickett, K., Loveman, E. \& Frampton, G. K. Surgery for weight loss in adults. Cochrane Database Syst Rev, (8), CD003641 https://doi.org/10.1002/14651858.CD003641 (2014).

14. Serrano, O. K. et al. Weight loss outcomes and complications from bariatric surgery in the super super obese. Surgical endoscopy, 30 (6), 2505-2511 https://doi.org/10.1007/s00464-015-4509-y (2016).

15. Leykin, Y. et al. Anesthetic Management of Morbidly Obese and Super-Morbidly Obese Patients Undergoing Bariatric Operations: Hospital Course and Outcomes. OBES SURG, 16, 1563-1569 https://doi.org/10.1381/096089206779319491 (2006).

16. Dillemans, B., Van Cauwenberge, S., Agrawal, S., Van Dessel, E. \& Mulier, J. P. Laparoscopic adjustable banded roux-en-y gastric bypass as a primary procedure for the super-super-obese (body mass index $>60$ kg/m²). BMC Surg, 10, 33 https://doi.org/10.1186/1471-2482-10-33 (2010).

17. Consensus Development Conference Panel. Gastrointestinal surgery for severe obesity. Ann Intern Med. 1991;115(12):956-961. 
18. Legtenhorst, B. R. et al. Effect of primary versus revisional Roux-en-Y gastric bypass: inferior weight loss of revisional surgery after gastric banding. Surg Obes Relat Dis, 9 (2), 253-258 https://doi.org/10.1016/j.soard.2012.01.022 (2013).

19. Van Rutte, P. W., Smulders, J. F., De Zoete, J. P. \& Nienhuijs, S. W. Indications and short-term outcomes of revisional surgery after failed or complicated sleeve gastrectomy. OBES SURG, 22 (12), 1903-1908 https://doi.org/10.1007/s11695-012-0774-1 (2012).

20. Himpens, J., Coromina, L., Verbrugghe, A. \& Cadière, G. B. Outcomes of revisional procedures for insufficient weight loss or weight regain after Roux-en-Y gastric bypass. Obes Surg, 22 (11), 1746$1754 \mathrm{https} / / /$ doi.org/10.1007/s11695-012-0728-7 (2012).

21. Bessler, M. et al. Adjustable gastric banding as a revisional bariatric procedure after failed gastric bypass-intermediate results. Surg Obes Relat Dis. 2010;6(2010):31-35. doi: 10.1016/j.soard.2009.09.018.

22. Kaly, P. et al. Unrealistic weight loss expectations in candidates for bariatric surgery. Surg Obes Relat Dis, 4 (1), 6-10 https://doi.org/10.1016/j.soard.2007.10.012 (2008).

23. Page, A. J., Symonds, E., Peiris, M., Blackshaw, L. A. \& Young, R. L. Peripheral neural targets in obesity. Br J Pharmacol, 166 (5), 1537-1558 https://doi.org/10.1111/j.1476-5381.2012.01951.x (2012).

24. Gibbons, C., Hopkins, M., Beaulieu, K., Oustric, P. \& Blundell, J. E. Issues in Measuring and Interpreting Human Appetite (Satiety/Satiation) and Its Contribution to Obesity. Curr Obes Rep, 8 (2), 77-87 https://doi.org/10.1007/s13679-019-00340-6 (2019).

25. Sinha, A., Jayaraman, L., Punhani, D. \& Chowbey, P. Enhanced Recovery after Bariatric Surgery in the Severely Obese, Morbidly Obese, Super-Morbidly Obese and Super-Super Morbidly Obese Using Evidence-Based Clinical Pathways: A comparative Study. Obes Surg, 27 (3), 560-568 https://doi.org/10.1007/s11695-016-2366-y (2017).

26. LABS Writing Group for the LABS Consortium et al. Relationship of body mass index with demographic and clinical characteristics in the Longitudinal Assessment of Bariatric Surgery (LABS). Surg Obes Relat Dis, 4 (4), 474-480 https://doi.org/10.1016/j.soard.2007.12.002 (2008).

27. Bettencourt-Silva, R. et al. Carvalho D. Comparative Effectiveness of Different Bariatric Procedures in Super Morbid Obesity. Obes Surg, 29 (1), 281-291 https://doi.org/10.1007/s11695-018-3519-y (2019).

28. Myers, J. A., Sarker, S. \& Shayani, V. Treatment of massive super-obesity with laparoscopic adjustable gastric banding. Surg Obes Relat Dis, 2 (1), 37-40 discussion 40https://doi.org/10.1016/j.soard.2005.09.015 (2006).

29. Torchia, F. et al. LapBand System in super-superobese patients (>60 kg/m2): 4-year results. Obes Surg, 19 (9), 1211-1215 https://doi.org/10.1007/s11695-008-9760-z (2009).

30. Cho, E. J. \& Kim, S. M. Explantation of Adjustable Gastric Bands: An Observation Study of 10 Years of Experience at a Tertiary Center. Yonsei Med J, 60 (8), 782-790 https://doi.org/10.3349/ymj.2019.60.8.782 (2019). 
31. Langer, F. B. et al. Sleeve gastrectomy and gastric banding: effects on plasma ghrelin levels. Obes Surg, 15 (7), 1024-1029 https://doi.org/10.1381/0960892054621125 (2005 Aug).

32. Gil-Rendo, A. et al. Arjona Medina I, Martín Fernández J. Laparoscopic Sleeve Gastrectomy for HighRisk Patients in a Monocentric Series: Long-Term Outcomes and Predictors of Success. Obes Surg, 29 (11), 3629-3637 https://doi.org/10.1007/s11695-019-04044-7 (2019).

33. Villamere, J., Gebhart, A., Vu, S. \& Nguyen, N. Body mass index is predictive of higher in-hospital mortality in patients undergoing laparoscopic gastric bypass but not laparoscopic sleeve gastrectomy or gastric banding. Am Surg, 80 (10), 1039-1043 https://doi.org/10.1177/000313481408001028 (2014).

34. Gonzalez-Heredia, R. et al. Surgical management of super-super obese patients: Roux-en-Y gastric bypass versus sleeve gastrectomy. Surg Endosc, 30, 2097-2102 https://doi.org/10.1007/s00464015-4465-6 (2015).

35. Arapis, K. et al. Outcomes of Roux-en-Y gastric bypass versus sleeve gastrectomy in super-superobese patients (BMI $\geq 60 \mathrm{~kg} / \mathrm{m} 2$ ): 6-year follow-up at a single university. Surg Obes Relat Dis, 15 (1), 23-33 https://doi.org/10.1016/j.soard.2018.09.487 (2019).

36. Nasser, H. et al. Comparison of early outcomes between Roux-en-Y gastric bypass and sleeve gastrectomy among patients with body mass index $\geq 60 \mathrm{~kg} / \mathrm{m} 2$. Surg Endosc. 2020 Jun 22. doi: 10.1007/s00464-020-07750-x.

37. Regan, J. P., Inabnet, W. B., Gagner, M. \& Pomp, A. Early experience with two-stage laparoscopic Rouxen-Y gastric bypass as an alternative in the super-super obese patient. Obes Surg, 13 (6), 861-864 https://doi.org/10.1381/096089203322618669 (2003).

38. Al-Khyatt, W., Ryall, R., Leeder, P., Ahmed, J. \& Awad, S. Predictors of Inadequate Weight Loss After Laparoscopic Gastric Bypass for Morbid Obesity. Obes Surg, 27 (6), 1446-1452 https://doi.org/10.1007/s11695-016-2500-x (2017).

39. Ochner, C. N., Jochner, M. C., Caruso, E. A., Teixeira, J. \& Xavier Pi-Sunyer, F. Effect of preoperative body mass index on weight loss after obesity surgery. Surg Obes Relat Dis, 9 (3), 423-427 https://doi.org/10.1016/j.soard.2012.12.009 (2013).

40. Madhok, B. et al. Management of Super-super Obese Patients: Comparison Between Mini (One Anastomosis) Gastric Bypass and Sleeve Gastrectomy. Obes Surg, 26 (7), 1646-1649 https://doi.org/10.1007/s11695-016-2181-5 (2016).

41. Aminian, A. et al. Failed Surgical Weight Loss Does Not Necessarily Mean Failed Metabolic Effects. Diabetes Technol Ther, 17 (10), 682-684 https://doi.org/10.1089/dia.2015.0064 (2015).

42. Runkel, N. \& Brydniak, R. Surgical Treatment of Metabolic Syndrome. Visc Med, 32 (5), 352-356 https://doi.org/10.1159/000449110 (2016).

43. Lunel, T. et al. Third bariatric procedure for insufficient weight loss or weight regain: how far should we go?Surg Obes Relat Dis. 2021Jan;17(1):96-103. doi: 10.1016/j.soard.2020.08.032.

44. Kushnir, L. et al. Is BMI greater than $60 \mathrm{~kg} / \mathrm{m} 2$ a predictor of higher morbidity after laparoscopic Roux-en-Y gastric bypass? Surg Endosc, 24 (1), 94-97 https://doi.org/10.1007/s00464-009-0552-x 
(2010).

45. Omalu, B. I. et al. Death rates and causes of death after bariatric surgery for Pennsylvania residents, 1995 to 2004. Arch Surg, 142 (10), 923-928 https://doi.org/10.1001/archsurg.142.10.923 (2007).

\section{Tables}

Table 1-Demographic patient characteristics.

\begin{tabular}{|lll|}
\hline Characteristic & Average (N60) & SD/95\%Cl \\
\hline Age (years) & 41.5 & $11.25 / 1.45$ \\
\hline Weight (Kgs) & 171.96 & $27.12 / 3.50$ \\
\hline Height (Cm) & 163.75 & $12.19 / 1.57$ \\
\hline BMI (Kg/m²) & 63.81 & $4.77 / 0.62$ \\
\hline Operative Time (min.) & 126.15 & $63.32 / 8.17$ \\
\hline Follow-up (Month) & 73.57 & $39.33 / 5.08$ \\
\hline & $\mathbf{N}$ & Percent \\
\hline Male & 20 & $33.33 \%$ \\
\hline Female & 40 & $66.67 \%$ \\
\hline Healthy & 12 & $20 \%$ \\
\hline Co-morbidities & 48 & $80 \%$ \\
\hline LSG & 40 & $66.67 \%$ \\
\hline LSAGBP & 15 & $25 \%$ \\
\hline LRYBP & 5 & $8.33 \%$ \\
\hline Revision of LAGB & 9 & $15 \%$ \\
\hline Revision of LSG & 5 & $8.33 \%$ \\
\hline Primary Procedure & 46 & $76.67 \%$ \\
\hline
\end{tabular}

Table 2- Co-morbidities and post-bariatric surgery outcomes. 


\begin{tabular}{|c|c|c|c|c|c|}
\hline \multirow[b]{3}{*}{ Co-morbidity } & \multicolumn{2}{|c|}{ Preoperative } & \multicolumn{3}{|l|}{ Postoperative } \\
\hline & & & Improvement & Remission & No-changes \\
\hline & $\mathbf{N}$ & Percent & $\mathbf{N}(\%)$ & $\mathbf{N}(\%)$ & $\mathbf{N}(\%)$ \\
\hline Fatty Liver & 23 & $38.33 \%$ & $7(30.43 \%)$ & 10 (43.48\%) & $6(26.09 \%)$ \\
\hline Diabetes Type II & 18 & $30 \%$ & 7 (38.89\%) & 7 (38.89\%) & $4(22.22 \%)$ \\
\hline HTN & 17 & $28.33 \%$ & 5 (29.41\%) & 0 & $12(70.59 \%)$ \\
\hline Hyperlipidemia & 10 & $16.67 \%$ & $6(60 \%)$ & $1(10 \%)$ & $3(30 \%)$ \\
\hline Sleep Apnea & 7 & $11.67 \%$ & $1(14.29 \%)$ & 5 (71.43\%) & $1(14.29 \%)$ \\
\hline Asthma & 5 & $8.33 \%$ & $2(40 \%)$ & $3(60 \%)$ & 0 \\
\hline Knee Pain & 4 & $6.67 \%$ & $3(75 \%)$ & 0 & $1(25 \%)$ \\
\hline Back Pain & 2 & $3.33 \%$ & $1(50 \%)$ & 0 & $1(50 \%)$ \\
\hline Depression & 2 & $3.33 \%$ & $1(50 \%)$ & 0 & $1(50 \%)$ \\
\hline GERD & 3 & $5 \%$ & 1 (33.33\%) & $2(66.67 \%)$ & 0 \\
\hline SVT & 2 & $3.33 \%$ & 0 & 0 & $2(100 \%)$ \\
\hline Infertility & 1 & $1.67 \%$ & 0 & 0 & $1(100 \%)$ \\
\hline Breast Cancer & 1 & $1.67 \%$ & 0 & 0 & $1(100 \%)$ \\
\hline Fibromyalgia & 1 & $1.67 \%$ & $1(100 \%)$ & 0 & 0 \\
\hline Cirrhosis & 1 & $1.67 \%$ & 0 & 0 & $1(100 \%)$ \\
\hline Hypothyroidism & 3 & $5 \%$ & 1 (33.33\%) & 0 & $2(66.67 \%)$ \\
\hline Drug Abuse & 1 & $1.67 \%$ & 0 & $1(100 \%)$ & 0 \\
\hline PTC & 1 & $1.67 \%$ & $1(100 \%)$ & 0 & 0 \\
\hline No Disease & 12 & $20 \%$ & - & - & - \\
\hline
\end{tabular}

The most common co-morbidities in patients with BMI $\geq$ than 60 are fatty liver, Diabetes type II, HTN and hyperlipidemia. The results show that the metabolic changes induced by bariatric surgery persist despite inadequate weight loss.

Abbreviations: N- Number of patients, HTN- Hypertension, GERD- Gastro-esophageal reflux disease, SVTSupraventricular tachycardia, and PTC- Pseudo tumor cerebri.

\section{Figures}




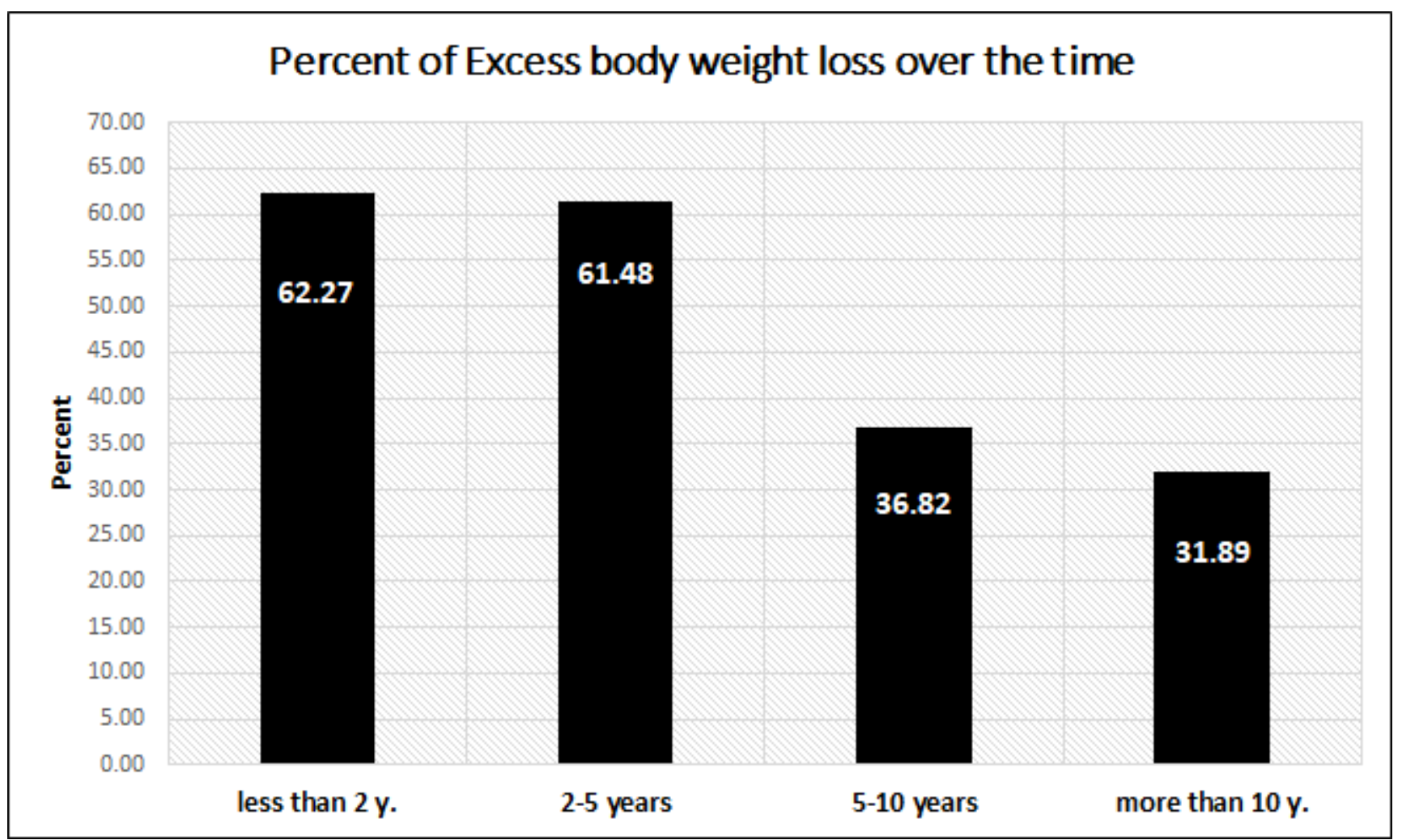

Figure 1

Percent of excess body weight loss over the time. The weight loss is demonstrated until 2 years follow-up, until 5 years, until 10 years and more than 10 years follow-up, corroborating gradual weight gain the further we get from the surgery. 


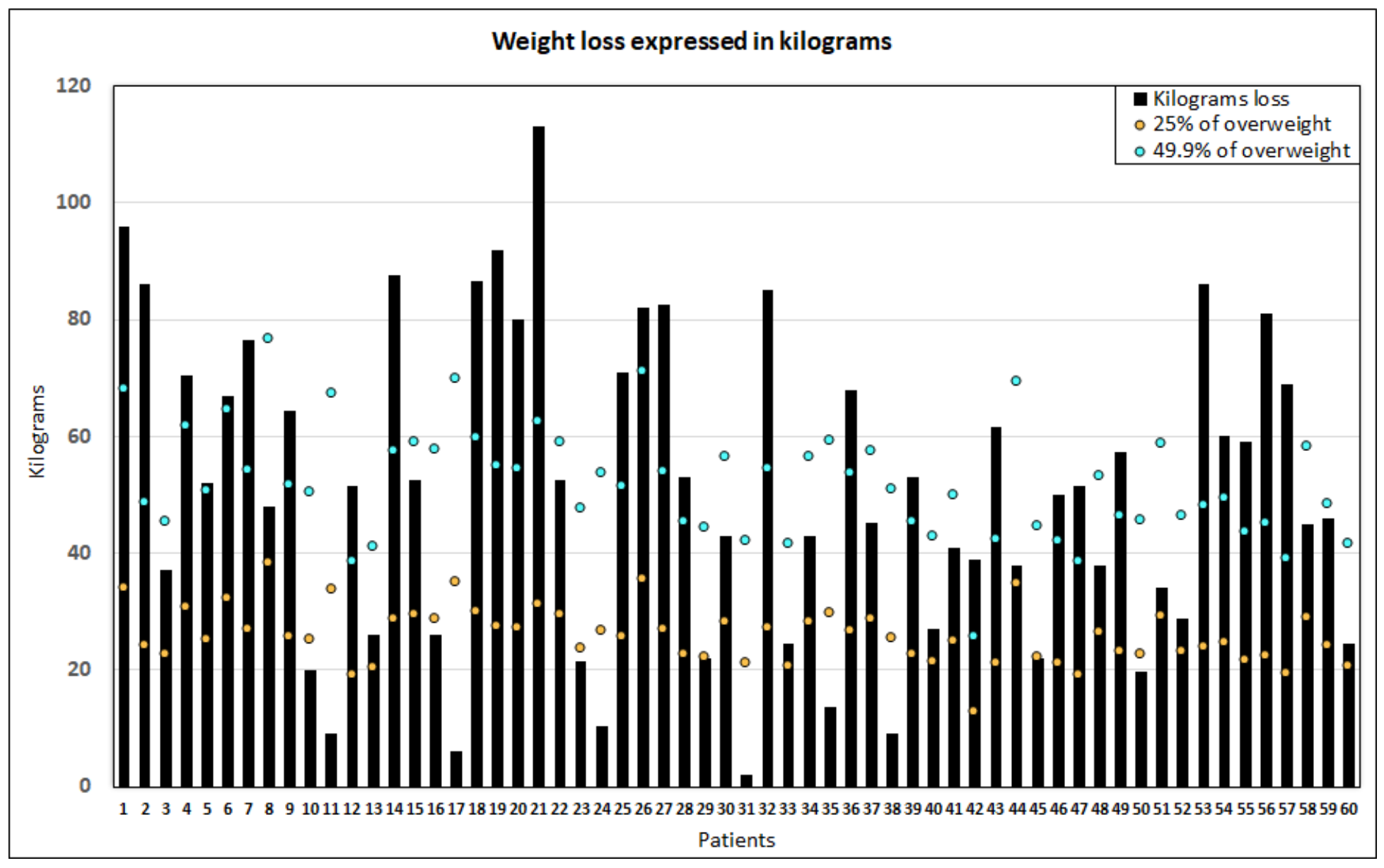

Figure 2

Wight loss expressed in kilograms. The percentage of excess weight loss is expressed here as well as the corresponding point in each patient has been marked at $25 \%$ of the weight lost and $50 \%$ of excess weight lost, which shows the high rate of failure of weight loss expected in each patient. 


\section{Percent of weight loss per type of bariatric surgery}

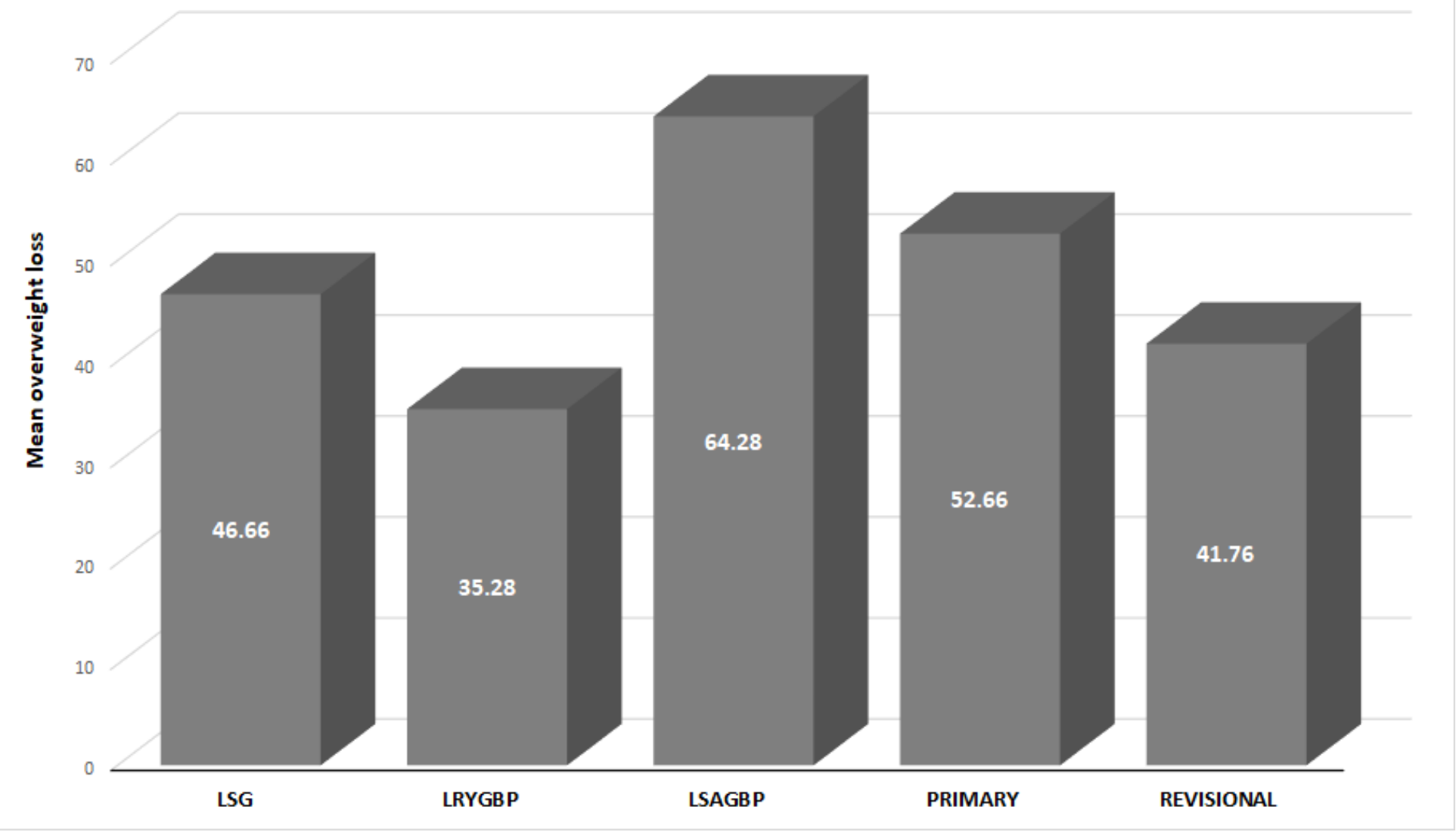

Figure 3

Mean EBW loss per type of bariatric surgery. One anastomosis gastric bypass is the surgery that provided greater weight loss than Sleeve gastrectomy and Roux-en-Y gastric bypass, as well as revisional surgery of previous bariatric procedures provokes less weight loss than primary bariatric surgeries. Abbreviations: EBW- excess body weight.

\section{Supplementary Files}

This is a list of supplementary files associated with this preprint. Click to download.

- DATA1.xlsx 